\title{
EFFECTS OF EXERGAMES AND RESISTANCE TRAINING ON WELL-BEING IN OLDER ADULTS: A RANDOMIZED CLINICAL TRIAL
}

\author{
Efeitos dos exergames e treinamento contra resistência \\ no bem-estar de adultos mais velhos: um ensaio clínico randomizado
}

\author{
Vandrize Meneghinia ${ }^{(\mathbb{D})}$, Eduardo Hauser ${ }^{\mathrm{a}}(\mathbb{D}$, \\ Camilo Luis Monteiro Lourençoa ${ }^{\mathbb{D}}$, Aline Rodrigues Barbosab ${ }^{\mathrm{B}}$
}

\begin{abstract}
OBJECTIVE: To analyze the effects of an exergame-based training compared to resistance training on the quality of life and symptoms of depression in older adults. METHODS: This was a two-arm, non-blinded, randomized clinical trial. Thirty-five participants (62.09 \pm 7.11 years) were randomized either on the Exergame-based Training Group $(n=17)$ or the Resistance Training Group $(n=18)$. Sessions lasted 50 to 60 minutes, three times per week, for 13 weeks. For the Exergame-based Training Group, we used games that simulate sports and adventure activities through Xbox360 Kinect ${ }^{T M}$. The Resistance Training Group performed ten exercises per session for upper and lower limbs using free weights and machines, following $\vdash \quad$ linear periodization and individualized loads. Quality of life and symptoms of depression were assessed using the World Health Organization Quality of Life assessment - an abbreviated version (WHOQOL-BREF) and the Geriatric Depression $\underset{\sim}{\sim}$ Scale, respectively. We performed a two-way analysis of variance $(p \leq 0.05)$. RESULTS: Only time effects were identified for in overall quality of life, general health, and symptoms of depression. After the intervention, overall quality of life score increased ( $3.82 \pm 0.95$ versus $4.18 \pm 0.53, p=0.05)$, whereas symptoms of depression decreased $(3.35 \pm 1.73$ versus $2.59 \pm 1.54, p=0.02)$ in the Exergame-based Training Group, and the general health improved in the Resistance Training Group (3.78 \pm 0.81 versus $4.11 \pm 0.68, p=0.05$ ) compared with the baseline scores. CONCLUSION: Both training groups improved different aspects of quality of life. The Exergaming-based Training Group improved the overall perception, whereas the Resistance Training Group improved the general health-related perception. Participants in the Exergame-based Training Group also decreased the number of symptoms of depression.
\end{abstract}

KEYWORDS: exercise; virtual reality exposure therapy; aging.

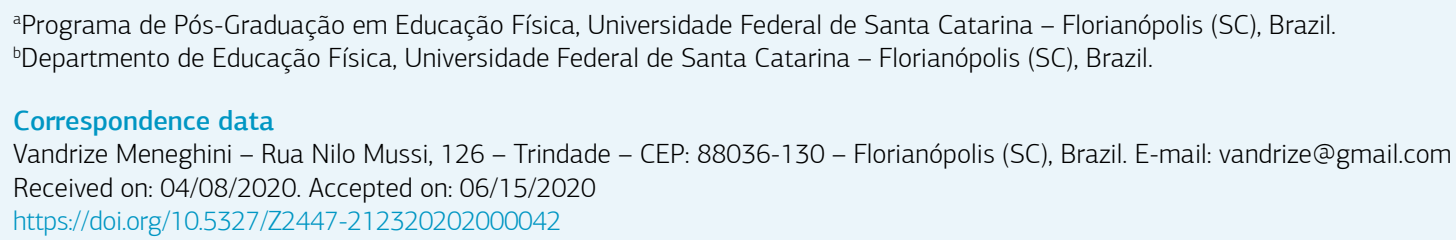


OBJETIVO: Analisar os efeitos de um treinamento baseado em exergames comparado ao treinamento contra resistência na qualidade de vida e nos sintomas depressivos em adultos mais velhos. METODOLOGIA: Trata-se de um estudo clínico randomizado, com dois braços e não cego. Trinta e cinco participantes (62,09 \pm 7,11 anos) foram randomizados para o Grupo de Treinamento com Exergames ( $n=17$ ) ou Treinamento de Resistência $(n=18)$. As sessões tiveram duração de 50 a 60 minutos, três vezes por semana, durante 13 semanas. Para o Grupo de Treinamento com Exergames, foram utilizados jogos que simulavam atividades esportivas e de aventura por meio do Xbox360 Kinect ${ }^{\top \mathrm{M}}$. O Grupo de Treinamento contra Resistência realizou dez exercícios por sessão, para membros superiores e inferiores, utilizando pesos livres e máquinas, seguindo periodização linear e ajuste de carga individualizado. A qualidade de vida e os sintomas depressivos foram avaliados usando o instrumento de Qualidade de Vida da Organização Mundial da Saúde - versão abreviada (WHOQOL-BREF) e a Escala de Depressão Geriátrica, respectivamente. Foram realizadas análises de variância two-way ( $\leq 0,05)$. RESULTADOS: Apenas efeitos no tempo foram identificados para qualidade de vida geral, saúde geral e sintomas depressivos. Após a intervenção, o escore de qualidade de vida geral aumentou (3,82 \pm $0,95$ versus $4,18 \pm 0,53, p=0,05)$ e os sintomas depressivos diminuíram $(3,35 \pm 1,73$ versus $2,59 \pm 1,54, p=0,02)$ no Grupo de Treinamento com Exergames, e a saúde geral melhorou no Grupo de Treinamento contra Resistência (3,78 $\pm 0,81$ versus 4,11 $\pm 0,68$, $p=0,05)$ quando comparados com os escores da linha de base. CONCLUSÃO: Ambos os grupos de treinamento melhoraram diferentes aspectos da qualidade de vida. O Grupo de Treinamento com Exergames melhorou a percepção geral, enquanto o Grupo de Treinamento contra Resistência apresentou melhorias na percepção geral relacionada à saúde. Os participantes do Grupo de Treinamento com Exergames também diminuíram o número de sintomas depressivos.

PALAVRAS-CHAVE: exercício; terapia de exposição à realidade virtual; envelhecimento.

\section{INTRODUCTION}

The well-being is a relevant outcome on aging process. As a component of successful concept of aging, it is a complex construct, including multiple indicators ${ }^{1}$ and enclosing psychological and social dimensions. ${ }^{2}$ Quality of life (QoL) is a multidimensional and subjective construct without a universally accepted definition. According to the World Health Organization (WHO), ${ }^{3}$ the concept of QoL encompasses domains regarding physical and mental health, social interaction, and emotional well-being, which can be affected in the aging process. ${ }^{4}$ For older adults, the QoL perception has been associated with independence, autonomy, and social participation. Therefore, it includes feeling healthy, being able to self-care, doing activities that bring a sense of value and joy, feeling at peace, and having relationships that make them feel supported and enabling them to mean something for others. ${ }^{5}$ Hence, symptoms of depression are known to have a negative impact on the QoL in all dimensions. ${ }^{6}$

Regular physical activity is an effective strategy to improve physical and mental health and well-being of older adults, ${ }^{7}$ considering they are indicators related to QoL. In addition, physical activity has been shown to be effective in relieving symptoms of depression. ${ }^{8}$ However, the effects of physical activity still need to be further explored because the intervention characteristics and time may result in different effects on each domain of QoL and symptoms of depression. ${ }^{8,9}$

Resistance training (RT) can enhance functional parameters of muscle strength, endurance, and power, and it is recommended for adults and older adults. ${ }^{10}$ In addition, regular participation in supervised RT programs can be a preventive and therapeutic tool for different health outcomes, such as cardiovascular health, musculoskeletal disorders, weight management, disability, and mental health issues, ${ }^{11}$ which contribute to physical independence. Recently, some studies showed the positive effects of RT on different $\mathrm{QLL}$ domains, ${ }^{12,13}$ suggesting that muscular fitness improvement may be important for QoL in the aging process. However, other studies found no effect of RT on QoL. ${ }^{14,15}$ Evidence has been found that RT can result in positive effects on symptoms of depression. ${ }^{16}$

With the advancement of technology over the last decades, the effects of Exergaming-based Trainings (EXE), which combine electronic games and exercise, have been investigated in older adults. Many previous studies showed benefits of this intervention on physical, cognitive, and emotional aspects. ${ }^{17,18} \mathrm{~A}$ recent systematic review ${ }^{19}$ analyzed the effects of EXE on the QoL of older adults, and of the nine randomized controlled trials analyzed, only two showed favorable results for the Exergame Group. ${ }^{20,21}$ According to Cacciata et al., ${ }^{19}$ the heterogeneity of studies (sample, type of device, and environment) made it difficult to compare them, and further studies are needed to determine if EXE is effective to improve the QoL of older adults.

In this scenario, this study aimed to analyze the effect of EXE compared to RT on QoL and symptoms of depression in healthy older adults. We hypothesize that both interventions might result in improvements, but RT is likely better than EXE for those outcomes. 


\section{METHODS}

\section{Study design}

This is a randomized, non-blinded, active controlled clinical trial with a two-arm parallel design (1:1 allocation ratio). The study was approved by the Local Ethics Committee of Universidade Federal de Santa Catarina (Certificate of Presentation for Ethical Appreciation No. 64415516.8.0000.0121) and was registered in the Brazilian Clinical Trials Registry (No. RBR-7fh22d).

Regarding important changes to methods after the commencement of trial, this study was expected to be carried out in 16 weeks; however, the researchers decided to end it earlier due to the number of dropouts. Data collection and interventions were conducted in the Sports Center at Universidade Federal de Santa Catarina, from July to November 2017.

\section{Participants, setting, and recruitment}

The community-dwelling participants were recruited through electronic invitation, and the leaflets and posters were distributed in areas of the university and on its neighborhood, in June and July 2017. Men and women aged 50 years or older, who reported not having participated in professionally oriented strength or aerobic training in the previous month and had no contact with exergames in the previous 12 months were eligible to participate in this study. The exclusion criteria were diagnosis of Alzheimer's disease; Parkinson's disease; disabling neurological diseases; psychiatric comorbidities; serious metabolic and cardiovascular diseases; and orthopedic injury that made it difficult or avoided the performance of the proposed activities. During the study, participants were asked not to participate in another exercise program.

\section{Interventions}

The training sessions were held three times a week on alternate days, and each session lasted 50 to 60 minutes for 13 weeks. Initially, participants underwent three sessions where they became familiar with the exercises (using very light loads and reduced volume). Every session started with a warm-up exercise ( 5 minutes - joint mobility exercises) and finished with a cool-down practice (5 minutes - stretching and breathing exercises). All training sessions were supervised by physical education graduate and undergraduate students.

\section{Exergame group}

We used the Microsoft Xbox 360 console with Kinect $^{\mathrm{TM}}$ (Redmond, WA, USA) and games that simulate sports and adventure activities. The sessions were conducted primarily in pairs, in a room equipped with a projector, a white screen $(240 \times 180 \mathrm{~cm})$, and a speaker set. The selected activities are part of the Kinect Sports Ultimate Collection ${ }^{\mathrm{TM}}$ and Kinect Adventures ${ }^{\mathrm{TM}}$ collections. The sports games were divided into mini (short games, played individually) and complete (athletics, bowling, boxing, skiing, soccer, tennis, table tennis, and beach volleyball) games. At Kinect Adventures ${ }^{\mathrm{TM}}$, the following games were selected: Space Pop, River Rush, Reflex Ridge, and 20,000 Leaks. The sessions consisted of four different games, considering the balance between the physical requirements of each game. The intensity was individually increased by changing the difficulty of games (four different levels, from beginner to professional), considering the participant's performance.

\section{Resistance training group}

The prescription of a resistance exercise program was based on the recommendations of the American College of Sports Medicine and the American Heart Association. ${ }^{22}$ It was performed in a room equipped with free weights and machines $\left(\right.$ Righetto $\left.^{\circledast}\right)$. Participants performed ten exercises, following linear periodization and individualized loads: seated leg press, knee flexion, knee extension, seated calf raise, low row, chest fly machine, elbow flexion (dumbbell and barbell), elbow extension (machine and pulley), abdominal crunches, and trunk extension. Load was increased after considering the number of maximum repetitions in each series (three sets of eight to 17 repetitions). The loads were adjusted whenever the individual exceeded the number of prescribed maximum repetitions in the last set.

\section{Outcomes}

QoL was measured using the World Health Organization Quality of Life assessment, an abbreviated version (WHOQOL-BREF). ${ }^{23}$ This instrument consists of 26 questions (Q), comprising overall (Q1) and general health (Q2) questions, as well as the following domains: physical health (Q3, Q4, Q10, Q15-Q18), psychological (Q5-Q7, Q11, Q19, Q26), social relationships (Q20-Q22), and environment (Q8, Q9, Q12-Q14, Q23-Q25). The answer options were presented in a Likert scale, from 1 to 5 . Results for each domain were calculated and presented through means and standard deviations. ${ }^{23}$ This questionnaire presented satisfactory values of internal consistency, validity, and reliability. ${ }^{24}$

The Geriatric Depression Scale-15 (GDS-15), which is a 15-question instrument about feelings and life situations, was used to assess the symptoms of depression. It was developed and validated for measuring symptoms of depression in older people. ${ }^{25}$ 
Sample size

The a priori sample calculation considered a $5 \%$ significance level, and a $80 \%$ test power for repeated measures analysis of variance (ANOVA) with interactions. The moderate effect size $(f=0.5)^{26}$ was applied to verify a clinically significant difference, requiring a total of 34 participants.

\section{Randomization}

After the initial assessments, eligible participants were randomized to one of the intervention groups (EXE or RT), by a statistician with no research involvement. The following information was considered for the stratified randomization sampling, ensuring a similar distribution between groups: sex (female or male), age ( $\leq 64$ years or $>64$ years) and presence of hypertension (yes or no). Randomization was performed using the Microsoft Excel software, within each of the strata. The married couples were randomized together to avoid contamination. Participants were informed about the allocation through telephone contact.

\section{Statistical analysis}

The study used an intention-to-treat analysis and, in the case of missing data, the baseline observed carried forward (BOCF) imputation technique was used. It consists of repeating the baseline value for subsequent evaluations. This can be used when it is expected that the withdrawal of the study participant does not result in modification of the initial evaluation results (pre-intervention). ${ }^{27}$

We calculated frequencies, means $(M)$, and standard deviations (SD) of the baseline characteristics of the participants' sample. A two-way ANOVA was used to verify effects of the group (EXE, RT), time (baseline, week 13), and interaction (group*time). The Bonferroni test was selected to indicate the differences between multiple comparisons (post hoc). Effect sizes were presented as Cohen's $f$.

A 5\% level of statistical significance $(p \leq 0.05)$ was used. Data analysis was performed using the SPSS Statistics for Windows, version 16.0 (SPSS Inc., Chicago, Ill., USA).

\section{RESULTS}

Figure 1 shows the flow diagram of participant selection. From the 65 participants who were initially evaluated for eligibility, 35 were randomized into $\mathrm{EXE}$ ( $\mathrm{n}=17,11$ women, $M_{\text {age }}=63.82 \pm 7.19$ years old $)$ or RT ( $\mathrm{n}=18,11$ women, $M_{\text {age }}$ $=60.44 \pm 6.84$ years old) groups. After 13 weeks, 26 participants completed the study (72\%). Nine participants were not assessed at post-intervention, and their data were imputed to perform the analysis. The adherence in the sessions was $56 \%$
$(M=22$; min-max: $0-35)$ for the EXE Group and $62 \%$ $(M=23$; min-max: $0-38)$ for the RT Group. Both groups were similar for demographic characteristics and health perception (Table 1).

ANOVA results showed a time effect for overall QoL $(p=0.04, f=0.38)$, general health $(p=0.04, f=0.37)$, and psychological domain $(\mathrm{p}=0.03, \mathrm{f}=0.40)$, as seen in Table 2. There was no group or interaction effect $(p>0.05)$. Multiple comparisons showed that, after 13 weeks of training, the EXE Group increased the overall QoL score $(3.82 \pm 0.95$ versus $4.18 \pm 0.53, p=0.05)$, and the RT Group improved the general health $(3.78 \pm 0.81$ versus $4.11 \pm 0.68, p=0.05)$ compared with baseline scores. The psychological domain score increased in both groups, as follows: $\mathrm{EXE}(15.38 \pm 2.46$ versus $16.08 \pm 2.12)$ and RT $(16.00 \pm 2.02$ versus $16.44 \pm 2.21)$. However, this difference was not statistically significant $(p=0.06$ and $p=0.21$, respectively). There was only a time effect for symptoms of depression $(p=0.05, f=0.36)$, in which the EXE Group decreased the mean number of symptoms of depression reported after training $(3.35 \pm 1.73$ versus $2.59 \pm 1.54, \mathrm{p}=0.02$; for detailed information see Table 2 ). Sensitivity analyzes were performed using only the complete-case data (EXE: $n=12 ;$ RT: $n=14)$ and showed similar results.

There was no adverse event associated with RT. For the EXE Group, four adverse events occurred (mild-moderate degree): ankle injury (fifth session, at "River Rush" game), pain in the thigh muscle (fourth session, at "Body Ball" game), and big toe injury (10th and 25th sessions, at "Soccer" game).

The reasons for dropouts were: three participants (EXE $=2$ and $\mathrm{RT}=1)$ reported health problems not related to the interventions; one person was injured during a session of exergames; two people, in the RT Group, reported not liking the intervention; two participants reported difficulty with the schedule ( $\mathrm{RT}=1$ and $\mathrm{EXE}=1$ ); and one individual, in EXE Group, did not return to contact after randomization.

\section{DISCUSSION}

The aim of this study was to analyze the effect of EXE compared to RT on QoL and symptoms of depression in healthy older adults. Although exergaming was not superior to the resistance program, after 13 weeks of intervention, the scores for overall QoL and general health perceptions improved in the EXE and RT Groups, respectively. For the psychological dimension of QoL, the results suggest this domain was improved in the training groups, but the change was not statistically significant after the post-hoc comparison. There was a time effect in the number of symptoms of depression 


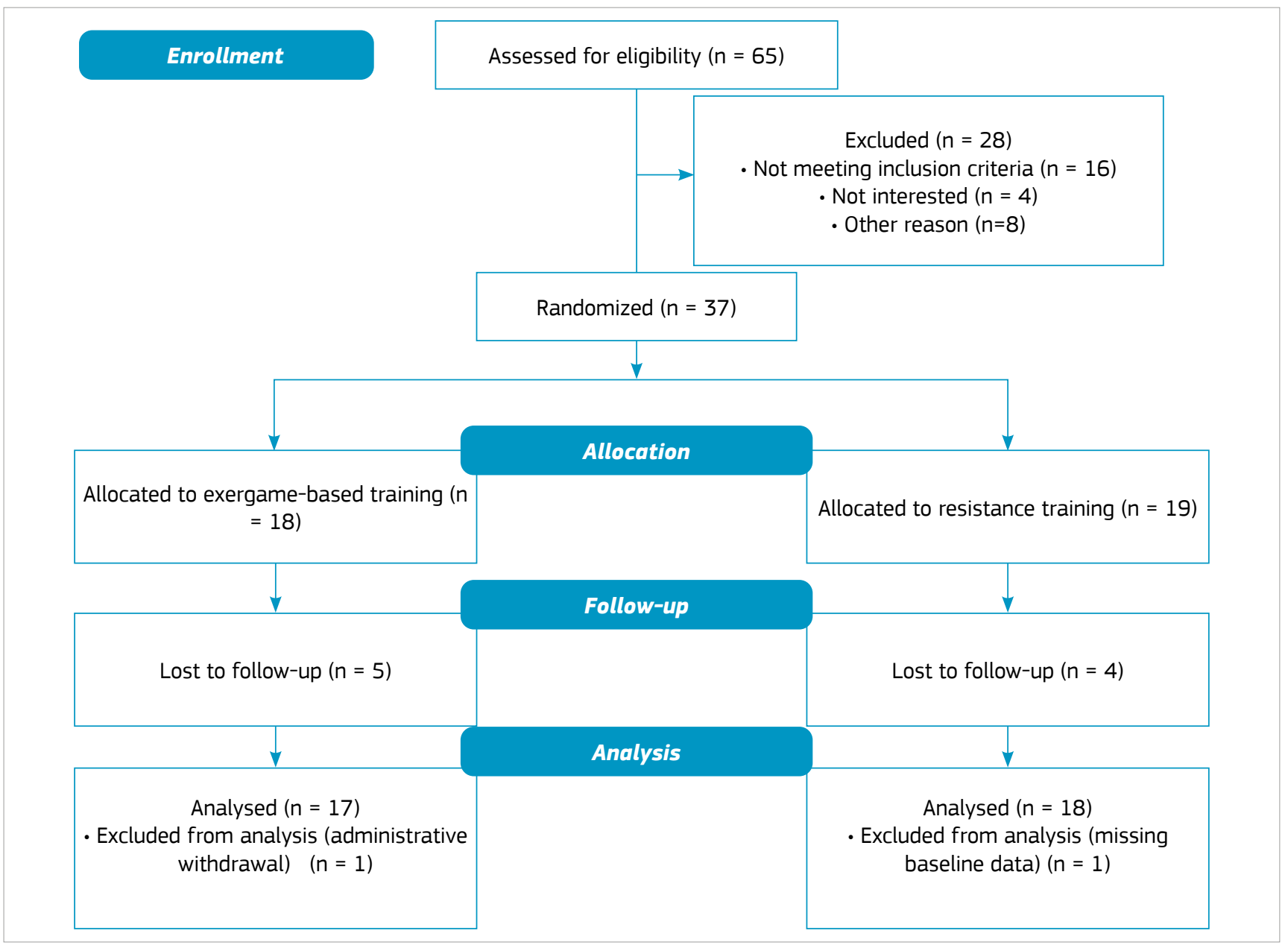

Figure 1 Flow diagram.

Table 1 Baseline characteristics of the participants.

\begin{tabular}{|c|c|c|c|}
\hline Variables & $\begin{array}{c}\text { All } \\
(n=35)\end{array}$ & $\begin{array}{l}\text { EXE Group } \\
(\mathrm{n}=17)\end{array}$ & $\begin{array}{l}\text { RT Group } \\
(n=18)\end{array}$ \\
\hline Age, years (SD) & $\begin{array}{l}62.09 \\
(7.11)\end{array}$ & $\begin{array}{l}63.82 \\
(7.19)\end{array}$ & $\begin{array}{l}60.44 \\
(6.84)\end{array}$ \\
\hline \multicolumn{4}{|l|}{ Sex, n } \\
\hline Female & 22 & 11 & 11 \\
\hline Male & 13 & 6 & 7 \\
\hline \multicolumn{4}{|l|}{ Education level, n } \\
\hline$<12$ years & 13 & 6 & 7 \\
\hline$\geq 12$ years & 22 & 11 & 11 \\
\hline \multicolumn{4}{|l|}{ General health, n } \\
\hline Very good/good & 26 & 10 & 16 \\
\hline Regular/poor/very poor & 9 & 7 & 2 \\
\hline
\end{tabular}

EXE: exergaming-based program; RT: resistance training; SD: standard deviation. that were reported, and the symptoms of depression mean decreased in the EXE Group after training.

The positive effects of EXE on different QoL domains are inconsistent..$^{20,28,29}$ Our results agree, in part, with other randomized intervention studies that used WHOQOL$\mathrm{BREF}^{29}$ and SF-36 ${ }^{20}$ to assess QoL. Konstantinidis et al. ${ }^{29}$ showed that after eight weeks of exergaming intervention (developed by the authors), participants (60 to 87 years) reported improvements in the physical, psychological, and environmental domains of QoL. Karahan et al. ${ }^{20}$ reported that the EXE Group (sports games, Xbox360 Kinect ${ }^{\mathrm{TM}}$ ) showed significant improvements in the physical functioning, social role functioning, physical role restriction, general health perceptions, and physical QoL domains.

In contrast to our results, a randomized controlled trial with residents of an independent living senior's housing ( $\mathrm{n}=32,63$ to 90 years) showed no significant change in SF-36 scores from pre-to post intervention. ${ }^{28}$ Differences in the results may be related to variability in exergaming programs, duration of intervention, frequency and session length, 
Table 2 Quality of life and symptoms of depression in exergaming-based training and resistance training.

\begin{tabular}{|c|c|c|c|}
\hline \multirow{2}{*}{ Variables } & Baseline & Post Intervention & \multirow{2}{*}{ Effects } \\
\hline & Mean \pm SD & Mean \pm SD & \\
\hline \multicolumn{2}{|c|}{ Overall QoL question } & & Interaction $\left(F_{1,33}=0.61 ; p=0.44 ; f=0.14\right)$ \\
\hline EXE & $3.82 \pm 0.95$ & $4.18 \pm 0.53^{*}$ & Inter $\left(F_{1,33}=0.14 ; p=0.71 ; f=0.06\right)$ \\
\hline RT & $4.00 \pm 0.69$ & $4.17 \pm 0.79$ & Intra $\left(F_{1,33}=4.76 ; p=0.04 ; f=0.38\right)$ \\
\hline \multicolumn{2}{|c|}{ General health question } & & Interaction $\left(F_{1,33}=0.43 ; p=0.52 ; f=0.11\right)$ \\
\hline EXE & $3.47 \pm 1.01$ & $3.65 \pm 0.70$ & Inter $\left(F_{1,33}=2.47 ; p=0.13 ; f=0.27\right)$ \\
\hline RT & $3.78 \pm 0.81$ & $4.11 \pm 0.68^{*}$ & Intra $\left(F_{1,33}=4.55 ; p=0.04 ; f=0.37\right)$ \\
\hline \multicolumn{2}{|c|}{ Physical health domain } & & Interaction $\left(F_{1,33}=0.21 ; p=0.65 ; f=0.08\right)$ \\
\hline EXE & $15.23 \pm 2.56$ & $15.53 \pm 2.68$ & Inter $\left(F_{1,33}=0.99 ; p=0.33 ; f=0.17\right)$ \\
\hline RT & $16.13 \pm 2.21$ & $16.13 \pm 2.28$ & Intra $\left(F_{1,33}=0.21 ; p=0.65 ; f=0.08\right)$ \\
\hline \multicolumn{2}{|c|}{ Psychological domain } & & Interaction $\left(F_{1,33}=0.26 ; p=0.62 ; f=0.09\right)$ \\
\hline EXE & $15.38 \pm 2.46$ & $16.08 \pm 2.12$ & Inter $\left(F_{1,33}=0.49 ; p=0.49 ; f=0.12\right)$ \\
\hline RT & $16.00 \pm 2.02$ & $16.44 \pm 2.21$ & Intra $\left(F_{1,33}=5.21 ; p=0.03 ; f=0.40\right)$ \\
\hline \multicolumn{2}{|c|}{ Social relationships domain } & & Interaction $\left(F_{1,33}=2.12 ; p=0.16 ; f=0.25\right)$ \\
\hline EXE & $14.43 \pm 2.63$ & $14.90 \pm 2.46$ & Inter $\left(F_{1,33}=0.02 ; p=0.88 ; f=0.03\right)$ \\
\hline RT & $15.19 \pm 3.11$ & $14.44 \pm 3.89$ & Intra $\left(F_{1,33}=0.11 ; p=0.75 ; f=0.05\right)$ \\
\hline \multicolumn{2}{|c|}{ Environmental domain } & & Interaction $\left(F_{1,33}=3.42 ; p=0.07 ; f=0.32\right)$ \\
\hline EXE & $14.59 \pm 2.13$ & $14.94 \pm 2.24$ & Inter $\left(F_{1,33}=0.05 ; p=0.83 ; f=0.03\right)$ \\
\hline RT & $15.13 \pm 2.18$ & $14.69 \pm 1.99$ & Intra $\left(F_{1,33}=0.04 ; p=0.84 ; f=0.03\right)$ \\
\hline \multicolumn{2}{|c|}{ Symptoms of depression } & & Interaction $\left(F_{1,33}=2.33 ; p=0.14 ; f=0.27\right)$ \\
\hline EXE & $3.35 \pm 1.73$ & $2.59 \pm 1.54^{*}$ & Inter $\left(F_{1,33}=1.06 ; p=0.31 ; f=0.18\right)$ \\
\hline RT & $2.28 \pm 2.85$ & $2.17 \pm 2.53$ & Intra $\left(F_{1,33}=4.19 ; p=0.05 ; f=0.36\right)$ \\
\hline
\end{tabular}

*Significant difference between pre and post-intervention ( $p \leq 0.05)$.

intensity of exercises, study setting, number of participants, and degree of adherence. ${ }^{19}$

According to our results, the RT Group showed improvements in the score for the general health question, which is partially consistent with previous randomized studies ${ }^{30}$ or studies without a Control Group. ${ }^{12}$ Using SF-12 to assess QoL, Haraldstad et al. ${ }^{12}$ showed that older men undergoing 12 weeks of RT improved their QoL in aspects such as role, and physical and general health. Pedersen et al. ${ }^{30}$ assessed the participation in both team sports training and $\mathrm{RT}$ using the SF-12 questionnaire, and the scores for general and health-related QoL improved in that group compared with the Control Group. The underlying reasons why RT may have positive effects on adult health-related QoL may be due to muscular adaptations (e.g., improvements in muscle strength, muscle mass) and consequent improvements in functional and physical capacities. ${ }^{31}$ This may be positive for the perception of their own health, thereby improving their mood and well-being feeling and contributing to better psychological functioning.

The positive effects of EXE on emotional aspects ${ }^{18}$ and mood ${ }^{32}$ may partly explain our results on symptoms of depression and tendency for improvement in the psychological QoL dimension. Kirk et al. ${ }^{32}$ investigated healthy older adults and they showed that only one session of Wii Sports and Wii Fit games provided positive mood changes. Data from the study by $\mathrm{Li}$ et al. ${ }^{18}$, which was performed with 102 individuals (55 years and over), showed that after 
six weeks of intervention (once a week), exergames led to more positive emotions and less subthreshold depression than traditional exercises. In the present study, performing the games in pairs allowed social interaction between the participants. In addition, visual and audio performance feedback could make the exercises more interactive and enjoyable, ${ }^{33}$ contributing to the improvement in participants' psychological aspects.

One limitation of this study refers to the difficulty in controlling the intensity of the exergame training, even if it allows progression to higher levels, because of the influence of competitiveness on motivation. ${ }^{34}$ Additionally, the small sample size and the high number of dropouts may have affected the non-observation of changes between the groups. Despite the limitations, we observed clinically relevant changes in some dimensions of QoL. The main strengths of the present study were the trial with a randomized controlled group, qualified instructors in the intervention, and close follow-up. The study sample was heterogeneous (community-dwelling older people), increasing the external validity for the results.

\section{CONCLUSIONS}

This study showed that EXE and RT could improve the overall and health-related QoL, respectively, in older adults. Furthermore, exergame interventions have shown benefits by decreasing the number of symptoms of depression. Thus, this kind of exercise might be an additional method to improve QoL and health in the older population.
EXE were shown to be a new alternative to exercise and, similar to RT, could increase the levels of physical activity in older people, thereby increasing the number of people that reach the recommended levels of physical activity for health.

\section{ACKNOWLEDGEMENTS}

This study was financed in part by Coordenação de Aperfeiçoamento de Pessoal de Nível Superior - Brasil (CAPES) - Finance Code 001. The funding source was not neither involved in the conduction of the research nor in the preparation of the article.

\section{CONFLICT OF INTERESTS}

The authors declare no conflict of interests.

\section{FUNDING}

None.

\section{AUTHORS' CONTRIBUTION}

VM: conceptualization, methodology, formal analysis, investigation, writing - review \& editing. EH: writing original draft. CLML: formal analysis, investigation, writing - review \& editing. ARB: conceptualization, methodology, supervision, project administration, writing - review \& editing.

\section{REFERENCES}

1. Huta V, Waterman AS. Eudaimonia and its distinction from Hedonia: Developing a classification and terminology for understanding conceptual and operational definitions. J Happiness Stud. 2014;15:1425-56. https://doi.org/10.1007/s10902-013-9485-0

2. Prilleltensky I. Promoting well-being: time for a paradigm shift in health and human services. Scand J Publ Health. 2005;66:53-60. https://doi.org/10.1080/14034950510033381

3. World Health Organization. Measuring quality of life: The development of the World Health Organization quality of life instrument (WHOQOL). Geneva: World Health Organization; 1993.

4. Raggi A, Corso B, Minicuci N, Quintas R, Sattin D, De Torres L, et al. Determinants of quality of life in ageing populations: Results from a cross-sectional study in Finland, Poland and Spain. PLoS One. 2016;11(7):1-17. https://doi.org/10.1371/journal.pone.0159293

5. van Leeuwen KM, van Loon MS, van Nes FA, Bosmans JE, de Vet HCW, Ket JCF, et al. What does quality of life mean to older adults? A thematic synthesis. PLoS One. 2019;14(3):e0213263. https://dx.doi. org/10.1371\%2Fjournal.pone.0213263

6. Sivertsen H, Bjørkløf GH, Engedal K, Selbæk G, Helvik AS. Depression and quality of life in older persons: A review. Dement Geriatr Cogn Disord. 2015;40(5-6):311-39. https://doi.org/10.1159/000437299
7. Mikkelsen K, Stojanovska L, Polenakovic M, Bosevski M, Apostolopoulos V. Exercise and mental health. Maturitas. 2017;106:48-56. https:// doi.org/10.1016/j.maturitas.2017.09.003

8. Schuch FB, Vancampfort D, Richards J, Rosenbaum S, Ward PB, Stubbs B. Exercise as a treatment for depression: A meta-analysis adjusting for publication bias. J Psychiatr Res. 2016;77:42-51. https://doi. org/10.1016/j.jpsychires.2016.02.023

9. Awick EA, Ehlers DK, Aguiñaga S, Daugherty AM, Kramer AF, McAuley E. Effects of a randomized exercise trial on physical activity, psychological distress and quality of life in older adults. Gen Hosp Psychiatry. 2017;49:44-50. https://dx.doi.org/10.1016\%2Fj. genhosppsych.2017.06.005

10. Williams MA, Haskell WL, Ades PA, Amsterdam EA, Bittner V, Franklin $B A$, et al. Resistance exercise in individuals with and without cardiovascular disease: 2007 update: A scientific statement from the American Heart Association Council on Clinical Cardiology and Council on Nutrition, Physical Activity, and Metabolism. Circulation. 2007;116(5):572-84. https://doi.org/10.1161/circulationaha.107.185214

11. Westcott WL. Resistance training is medicine: Effects of strength training on health. Curr Sports Med. 2012;11(4):209-16. https://doi. org/10.1249/jsr.0b013e31825dabb8 
12. Haraldstad K, Rohde G, Stea TH, Lohne-Seiler H, Hetlelid K, Paulsen $\mathrm{G}$, et al. Changes in health-related quality of life in elderly men after 12 weeks of strength training. Eur Rev Aging Phys Act. 2017;14:8. https://dx.doi.org/10.1186\%2Fs11556-017-0177-3

13. Kekäläinen T, Kokko K, Sipilä S, Walker S. Effects of a 9-month resistance training intervention on quality of life, sense of coherence, and depressive symptoms in older adults: Randomized controlled trial. Qual Life Res. 2018;27:455-65. https://doi.org/10.1007/s11136017-1733-z

14. Bonganha V, Modeneze DM, Madruga VA, Vilarta R. Effects of resistance training (RT) on body composition, muscle strength and quality of life (QoL) in postmenopausal life. Arch Gerontol Geriatr. 2012;54(2):361-5. https://doi.org/10.1016/j.archger.2011.04.006

15. Sillanpää E, Häkkinen K, Holviala J, Häkkinen A. Combined strength and endurance training improves health-related quality of life in healthy middle-aged and older adults. Int J Sports Med. 2012;33(12):981-6. https://doi.org/10.1055/s-0032-1311589

16. Gordon BR, McDowell CP, Hallgren M, Meyer JD, Lyons M, Herring MP. Association of efficacy of resistance exercise training with depressive symptoms: meta-analysis and meta-regression analysis of randomized clinical trials. JAMA Psychiatry. 2018;75(6):566-76. https://doi.org/10.1001/jamapsychiatry.2018.0572

17. Guimarães AV, Barbosa AR, Meneghini V. Active videogame-based physical activity vs. aerobic exercise and cognitive performance in older adults: A randomized controlled trial. J Phys Educ Sport. 2018;18(1):203-9. https://doi.org/10.7752/jpes.2018.01026

18. Li J, Theng YL, Foo S, Xu X. Exergames vs. traditional exercise: Investigating the influencing mechanism of platform effect on subthreshold depression among older adults. Aging Ment Health. 2018;22(12):1634-41. https://doi.org/10.1080/13607863.2017.1 385722

19. Cacciata M, Stromberg A, Lee JA, Sorkin D, Lombardo D, Clancy S, et al. Effect of exergaming on health-related quality of life in older adults: A systematic review. Int J Nurs Stud. 2019;93:30-40. https://doi. org/10.1016/j.jijnurstu.2019.01.010

20. Karahan AY, Tok F, Taskin H, Küçüksaraç S, Basaran A, Yildirim P. Effects of exergames on balance, functional mobility, and quality of life of geriatrics versus home exercise programme: Randomized controlled study. Eur J Public Health. 2015;23(Suppl.):S14-8. https:// doi.org/10.21101/cejph.a4081

21. Morone G, Paolucci T, Luziatelli S, losa M, Piermattei C, Zangrando F, et al. Wii Fit is effective in women with bone loss condition associated with balance disorders: A randomized controlled trial. Aging Clin Exp Res. 2016;28(6):1187-93. https://doi.org/10.1007/s40520-016-0578-6

22. Nelson ME, Rejeski WJ, Blair SN, Duncan PW, Judge JO, King AC, et al. Physical activity and public health in older adults: Recommendation from the American College of Sports Medicine and the American Heart Association. Circulation. 2007;116(9):1094-105. https://doi. org/10.1161/CIRCULATIONAHA.107.185650
23. World Health Organization. WHOQOL-BREF: Introduction, administration, scoring and generic version of the assessment (Programme on mental health). Geneva: World Health Organization; 1996.

24. Fleck M, Louzada S, Xavier M, Chachamovich E, Vieira G, Santos L, et al. Application of the Portuguese version of the abbreviated instrument of quality life "WHOQOL-bref”. Rev Saúde Pública. 2000;34(2):17883. http://dx.doi.org/10.1590/\$0034-89102000000200012

25. Almeida OP, Almeida SA. Confiabilidade da versão brasileira da escala de depressão em geriatria (GDS) versão reduzida. Ara Neuropsiquiatr. 1999;57(2B):421-6. http://dx.doi.org/10.1590/ 50004-282X1999000300013

26. Cohen J. Statistical power analysis for the behavioral sciences. L. Erlbaum Associates [Internet]. Academic Press; 1988 [accessed on March 20, 2020]. Available in: https://www.sciencedirect.com/ book/9780121790608/statistical-power-analysis-for-the-behavioralsciences https://doi.org/10.1016/C2013-0-10517-X

27. European Medicines Agency. Guideline on Missing Data in Confirmatory Clinical Trials [Internet]. 2011 [accessed on Jan. 11, 2020]. Available in: https://www.ema.europa.eu/en/documents/scientific-guideline/ guideline-missing-data-confirmatory-clinical-trials_en.pdf

28. Franco JR, Jacobs K, Inzerillo C, Kluzik J. The effect of the Nintendo Wii Fit and exercise in improving balance and quality of life in community dwelling elders. Technol Health Care. 2012;20(2):95-115. https://doi. org/10.3233/thc-2011-0661

29. Konstantinidis El, Billis AS, Mouzakidis CA, Zilidou VI, Antoniou PE, Bamidis PD. Design, implementation, and wide pilot deployment of FitForAll: An easy to use exergaming platform improving physical fitness and life quality of senior citizens. IEEE J Biomed Health. 2016;20(1):189-200. https://doi.org/10.1109/jbhi.2014.2378814

30. Pedersen MT, Vorup J, Nistrup A, Wikman JM, Alstrøm JM, Melcher PS, et al. Effect of team sports and resistance training on physical function, quality of life, and motivation in older adults. Scand J Med Sci Sports. 2017;27(8):852-64. https://doi.org/10.1111/sms.12823

31. Ahtiainen JP, Walker S, Peltonen H, Holviala J, Sillanpää E, Karavirta L, et al. Heterogeneity in resistance training-induced muscle strength and mass responses in men and women of different ages. Age. 2016;38(1):10-23. https://dx.doi. org/10.1007\%2Fs11357-015-9870-1

32. Kirk A, MacMillan F, Rice M, Carmichael A. An exploratory study examining the appropriateness and potential benefit of the Nintendo Wii as a physical activity tool in adults aged $\geq 55$ years. Interact Comput. 2013;25(1):102-14. https://dx.doi.org/10.1093/iwc/iws004

33. Chao YY, Scherer YK, Montgomery CA. Effects of using Nintendo Wii ${ }^{\text {TM }}$ exergames in older adults: A review of the literature. J Aging Health. 2015;27(3):379-402. https://doi.org/10.1177/0898264314551171

34. Song H, Kim J, Tenzek KE, Lee KM. The effects of competition and competitiveness upon intrinsic motivation in exergames. Comput Human Behav. 2013;29(4):1702-8. https://doi.org/10.1016/j.chb.2013.01.042 